\title{
Migraine and risk of stroke and acute coronary syndrome in two case-control studies in the Danish population
}

This article was published in the following Dove Press journal:

Clinical Epidemiology

31 August 2017

Number of times this article has been viewed

\author{
Merete Osler ${ }^{1,2}$ \\ Ida Kim Wium-Andersen ${ }^{1,3}$ \\ Martin Balslev Jørgensen ${ }^{3}$ \\ Terese Sara Høj \\ Jørgensen ${ }^{1,2}$ \\ Marie Kim Wium-Andersen' \\ 'Research Center for Prevention \\ and Health, Rigshospitalet - \\ Glostrup, Copenhagen University, \\ Glostrup, Denmark; ${ }^{2}$ Department \\ of Public Health, Section of Social \\ Medicine, University of Copenhagen, \\ ${ }^{3}$ Department of Psychiatry O, \\ Rigshospitalet, Copenhagen, Denmark
}

Corresponding author: Merete Osler Research Center for Prevention and Health, Rigshospitalet- Glostrup, Nordre Ringvej 57, 2600 Glostrup, Denmark

$\mathrm{Tel}+4538633780$

Fax +4538633977

Email Merete.osler@regionh.dk
Introduction: Migraine has consistently been associated with increased risk of ischemic stroke, while the evidence for a relation with other types of stroke or coronary outcomes is limited. We examined the association between migraine and stroke and acute coronary syndrome (ACS) subtypes and the influence of potential confounding factors.

Methods: All first-time hospital contacts for stroke $(n=155,216)$ or ACS $(n=97,799)$ were identified in Danish National Patient Registers and matched with 2 control groups of the background population. A hospital diagnosis of migraine and use of migraine medication were the main exposures and associations (odds ratios [OR]) were estimated using multiple logistic regression. Confounding was also addressed by including use of general headache medication as a negative control exposure.

Results: The diagnosis of migraine was associated with increased odds of both stroke (OR age $<50$ years: 4.80 [95\% CI: 3.75-6.21]; OR crude, $_{\text {age }} \geq 50$ years: 1.91 [95\% CI: $1.67-2.19$ ]) and ACS ( $\mathrm{OR}_{\text {crude }}: 1.88$ [95\% CI: 1.53-2.32]), while the ORs for the associations between migraine medication and stroke and ACS were lower. Patients with a diagnosis of migraine or redeemed migraine medication had increased ORs of all stroke subtypes (ischemic, hemorrhagic stroke and transient ischemic attacks). The diagnosis of migraine was also associated with both angina and myocardial infarction (ST-elevation Myocardial Infarction [STEMI], non-STEMI and unspecified) with the highest OR for angina. These associations were not fully explained by adjustment for confounding co-variables or when compared with the negative control exposure that were assumed to be influenced by similar confounding factors, but no shared pathogenesis. Conclusion: Hospital-diagnosed migraine was associated with all stroke and ACS subtypes, with ischemic stroke and angina having the highest odds. Confounding did not explain the associations.

Keywords: migraine medication, stroke, acute coronary syndrome, case-control study, confounding

\section{Introduction}

Migraine is a common neurological disorder with a prevalence of $\sim 18 \%$. ${ }^{1}$ An aura, presumably triggered by cortical spreading depression, is present in up to $30 \%$ of migraineurs usually during the hour preceding the headache. ${ }^{2}$ Migraine has traditionally been viewed as a benign chronic episodic condition. However, accumulating evidence from smaller population- or hospital-based case-control ( $n=72-626$ stroke cases) and cohort ( $n=102-750$ stroke outcomes) studies suggests that migraine, especially with aura, doubles the risk of ischemic stroke. ${ }^{2-6}$ Data from these observational studies have been subject to meta-analyses, ${ }^{7-10}$ of which the most recent ${ }^{7,10}$ showed associations between migraine and both ischemic and hemorrhagic stroke with overall pooled 
odds ratios (OR) of 2.04 (95\% CI: $1.72-2.43)^{7}$ and 1.48 (95\% CI:1.46-1.88), ${ }^{10}$ respectively. Furthermore, subgroup analyses have revealed significant interactions for gender, age, smoking and oral contraceptive use with higher risk estimates in women, patients below age 45 years, smokers and women using oral contraceptives. ${ }^{3-5}$

To date, no clear mechanisms of the increased risk of stroke among patients with migraine have been identified and several hypotheses have been suggested. They have mainly been related to hemodynamic, inflammatory, coagulation, endothelial and vascular factors and medication. ${ }^{2,46,11}$ These mechanisms are shared with other vascular diseases and recently, migraine has also been associated with increased risk of ischemic heart disease ${ }^{12,13}$ and it has been suggested that migraine should be viewed as a systemic disorder affecting the endovascular system. ${ }^{5,6,11}$ However, while a number of studies have shown an association between migraine with aura and ischemic stroke, evidence is less consistent for hemorrhagic stroke, transient ischemic attacks (TIA), and ischemic heart disease as well for migraine without aura. In addition, many of the previous studies have only included a small number of confounding factors.

In the present study, we used data from 2 nationwide, register-based, case-control studies to examine the association between migraine with and without aura and stroke and acute coronary syndrome (ACS) subtypes. Based on the above evidence, we tested the following hypotheses: 1) migraine is associated with increased risk of stroke and ACS with the strongest association for ischemic stroke, TIA, myocardial infarction and angina, and 2) the associations between migraine and these cardiovascular outcomes are partly explained by cardiovascular risk factors, and 3) the risk is higher in females, the youngest age group, and among users of oral contraceptives or hormone replacement, and lower in patients using anti-thrombotic medication. Finally, we addressed potential confounding in 2 ways: 1) by considering the above cardiovascular risk factors and 2) as suggested by Gage et al,${ }^{14}$ including a negative control exposure (use of general headache medication) with assumed similar confounding but no shared pathogenesis.

\section{Methods}

\section{Study population}

All first-time hospital contacts for ACS or stroke in subjects aged 15 years or above occurring in Denmark from January 1, 2001 to December 31, 2009 or 2011, respectively, were included in the study. In total, 155,216 patients with stroke or TIA were identified in the nationwide Danish National
Patient Registry (DNPR) ${ }^{15}$ and the Danish Stroke Registry by primary in- or out-patient diagnoses with the following International Classification of Disease version 10 (ICD-10) codes: I61 hemorrhagic stroke ( $\mathrm{n}=14,843)$, I63 ischemic stroke $(n=58,299)$, I64 unspecified stroke $(n=73,715)$ and G45 TIA ( $\mathrm{n}=8,359)$. In total, 97,799 patients with ACS were identified in the DNPR by the following ICD-10 codes: I20.0 unstable angina pectoris $(\mathrm{n}=20,521), \mathrm{I} 21.0-\mathrm{I} 21.3 \mathrm{ST}$-elevation myocardial infarction (STEMI) $(\mathrm{n}=9,534)$, I21.4 nonSTEMI $(\mathrm{n}=25,058)$ and $\mathrm{I} 21.9$ unspecified acute myocardial infarction (AMI) $(\mathrm{n}=42,686)$. The DNPR provides full history of somatic diseases leading to hospital in- or out-patient visits by all citizens in Denmark since $1995 .{ }^{15}$ Two comparable control groups were sampled from the background population by matching with age, gender, and municipality at the time of stroke or ACS diagnosis using information from the Danish Civil Registration System (CPR). This register has allocated a unique personal identifier to everyone living in Denmark and keeps updated information on residency and vital status for each individual. The total number of subjects in the control groups was 156,905 and 99,618. The control groups were larger than the case group, as we excluded 1689 stroke and 1819 ACS cases who showed up not being incident as they had a prior register-based stroke or ACS diagnosis. The study was approved by the Danish Data Protection Agency. All data were retrieved from administrative registers and informed consent was not required of participants.

\section{Assessment of migraine}

Migraine was defined by a diagnosis in the DNPR or the Danish Psychiatric Central Register and/or redemption of migraine specific acute abortive (termed primary) medication or migraine preventive (termed secondary) medication in the Register of Medicinal Products Statistics. ${ }^{16}$ Diagnosis and medication were identified by ICD-10 and Anatomic Therapeutical Chemical (ATC) Classification System prior to the stroke, ACS or matching date. The ICD-10 and ATC codes are provided in the second column in Table 1. Both primary and secondary migraine medication needed prescription from a physician and dates for refill of prescribed medicine were registered in the Medical Products Statistics.

\section{Co-variables}

Based on reviews of the literature, ${ }^{4-10}$ a number of sociodemographic and clinical characteristics associated with migraine and cardiovascular disease were included. Information on age and gender was obtained from the CPR, while data on highest achieved education were retrieved from 


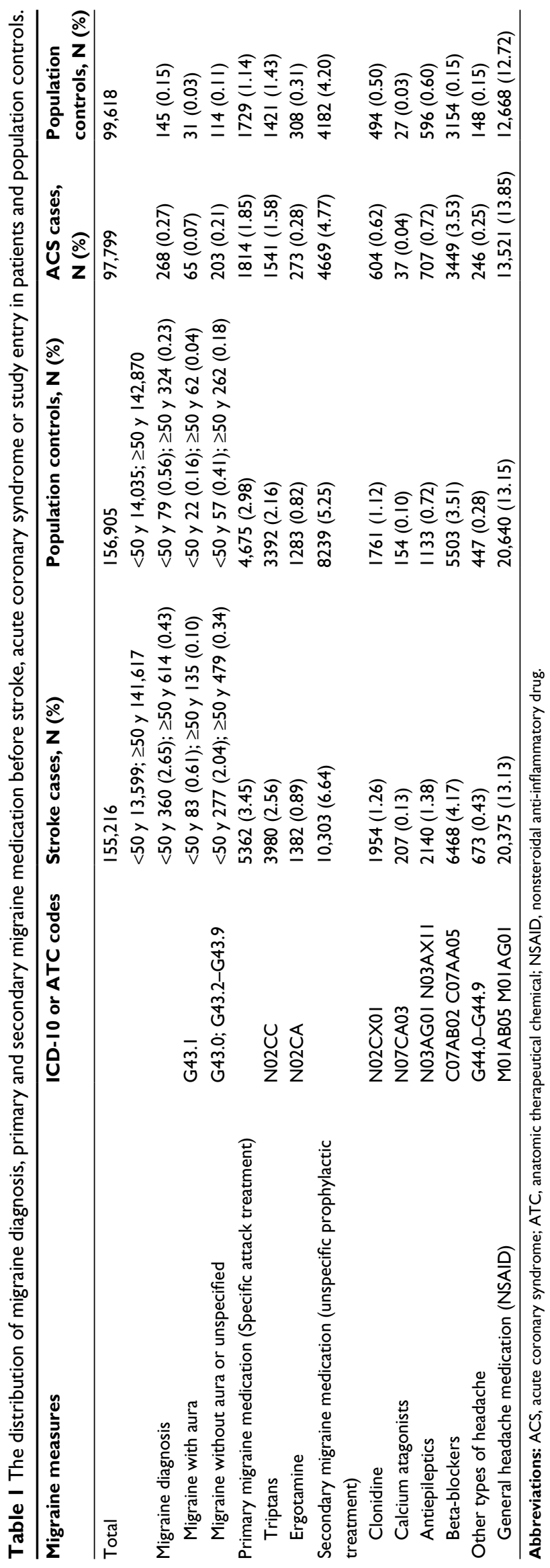

the Population Education Register. Education was grouped into basic (grades 7-9 of obligatory schooling), middle (high school, or vocational diploma) and higher (academic degree) education. Furthermore, diabetes mellitus, hypertension, alcohol-related disorders, COPD and depression were identified prior to stroke, ACS, or matching date by ICD-10 codes and ATC-codes described in Table S1. Information on current or former use of oral contraceptives, hormone replacement therapy, anti-thrombotic and -platelet medication (acetylsalicylic acid, clopidogrel, and warfarin), or statins prior to diagnosis was retrieved from the Register of Medical Products Statistics using the ATC-codes provided in Table S1.

\section{Statistical analyses}

Differences in the distribution of main exposures and covariables between cases and controls were examined using chi-square test. Logistic regression analyses were carried out to calculate odds ratios (OR) and 95\% CI for the association between migraine and stroke or ACS, and to adjust the estimates for the potentially confounding factors. As cases and controls represented the general population and exposure variables were collected prospectively, we assumed that the ORs will approximate relative risks. Models were tested by the Hosmer-Lemeshow chi-square test, which indicated reasonable fit. The influence of hormone use (oral contraceptives or hormone replacement therapy) was examined twice, both in models restricted to women and in models with men in the group coded as never. In models with $<50$ exposed, comorbidities and anti-thrombotic medication were entered as 2 combined yes/no variables. All analyses were repeated for each stroke or ACS sub-type. Any statistical interactions between migraine exposures and co-variables (age, gender, hormone use, and anti-thrombotic medication) were examined by adding an interaction term between migraine and each co-variable in the logistic models. Models with and without the interaction term were compared using likelihood ratio tests, thus interactions were tested on a multiplicative scale. Preliminary data analysis showed that OR differed for patients around age 50 years and the analyses were stratified accordingly. In supplementary analyses of confounding, we used general headache medication use (ATC codes provided in Table 1) as negative control exposure as this measure may have similar confounding as migraine but no assumed shared pathogenesis. ${ }^{14}$ Thus, users of general headache medication (nonsteroidal anti-inflammatory drugs) seemed to have more comorbidities than non-users, ${ }^{17}$ and the pattern of comorbidity seemed to be similar in pain medication users with and without 
chronic headache. ${ }^{18}$ Consequently, if the association between migraine and stroke and ACS was due to confounding, we expected to find a similar association between the negative control exposure and stroke and ACS, respectively. A significance level of 5\% was used and analyses were performed in STATA 14 (StataCorp LLC, College Station, TX, USA).

\section{Results}

\section{Migraine and stroke}

Among the 155,216 stroke patients, 974 (0.63\%) had a diagnosis of migraine and $5362(3.45 \%)$ had used primary migraine medication. Among controls, the corresponding numbers were $403(0.26 \%)$ and 4675 (2.98\%), respectively (Figure 1).

In crude analyses, stroke patients had increased likelihood of having a diagnosis of migraine $\left(\mathrm{OR}_{\text {crude }}\right.$, all types, age $<50$ years 4.80 [95\% CI: 3.75-6.21]); OR crude, $_{\text {all types, }}$ age $\geq 50$ years 1.91 [95\% CI: 1.67-2.19]). This was seen both for migraine with and without aura. Stroke patients also had increased odds of using primary migraine medication (OR: 1.17 [95\% CI: 1.11-1.21]) (Figure 1). Also, ORs were increased for both triptan (OR: 1.19 [95\% CI: 1.13-1.24]) and ergotamine use (OR: 1.08 [95\% CI:1.00-1.17]), but not significantly for ergotamine (Figure 1).
In both cases and controls, diagnosis of migraine and use of migraine medication were most frequent in individuals younger than 50 years, women, the highest educated, individuals with a diagnosis of depression or COPD, and among women who used hormones (Table S2). Adjustment for these cardiovascular risk factors attenuated the OR estimates, especially in analyses of migraine with aura (Figure 1). All analyses were repeated for the different stroke subtypes, which showed that diagnosis of migraine or use of migraine medication were associated with increased odds for all stroke subtypes (Table 2). For migraine with aura, the OR was lowest for hemorrhagic stroke and highest for TIA ( $p$ test for interaction $=0.02$ ), but the statistical power of the analyses was, despite the large sample size, limited due to the low number of individuals with diagnosis of migraine with aura. Consequently, the estimates had very wide CI.

In patients with migraine, $53.3 \%$ used primary migraine medication, but use of primary medication did not interact with the association between diagnosis of migraine and stroke. In both men and women, odds of having diagnosis of migraine were - as noted above - higher in stroke patients $<50$ years than in the older age group. The interaction terms were, however, not significant for gender, comorbidity, nor anti-thrombotic treatment (results not shown). Female

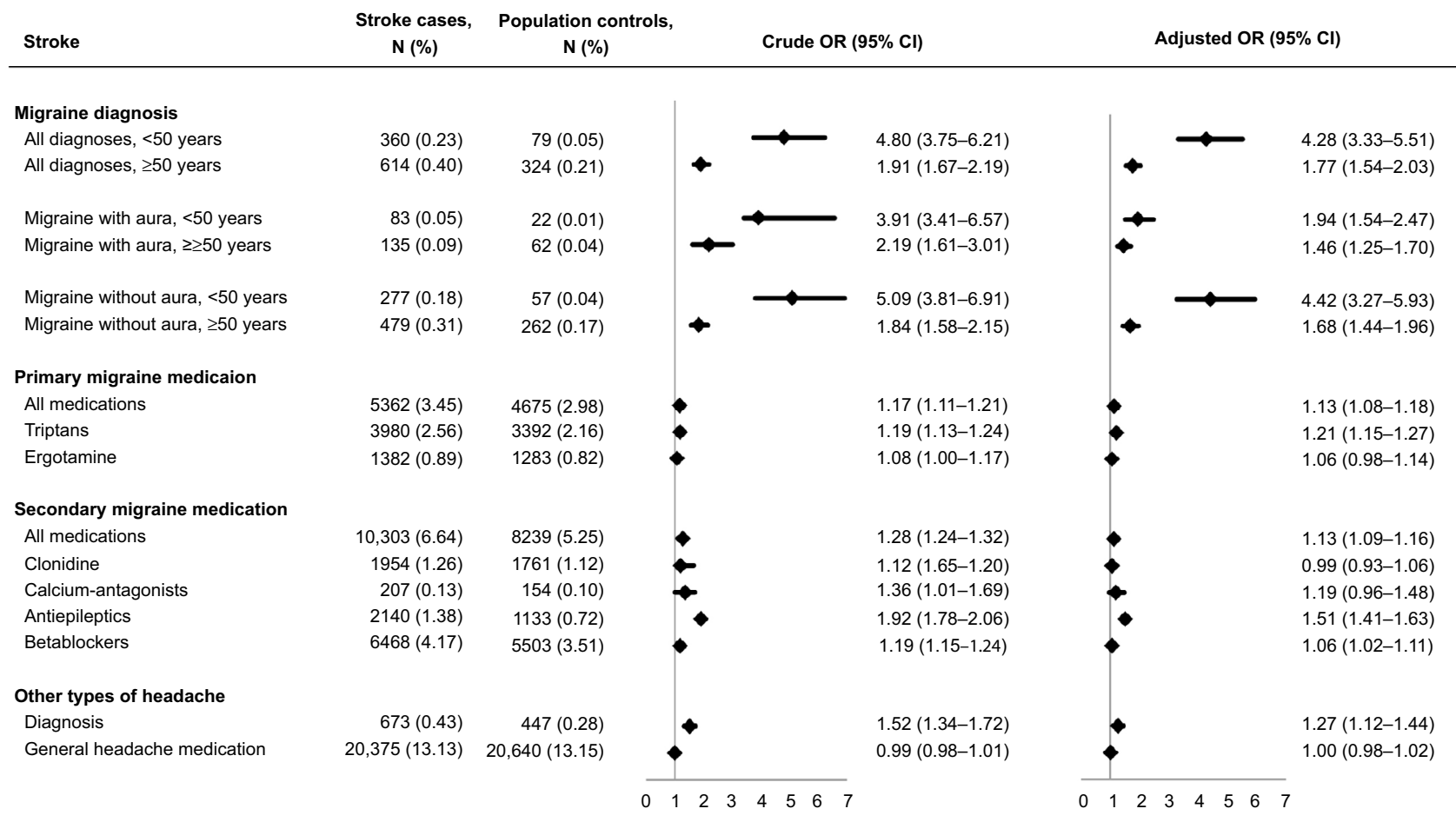

Figure I Associations (Crude and Adjusted OR and 95\% Cl) between migraine and stroke in 155,216 stroke patients and I56,905 controls.

Notes: Adjusted for age, gender, education, diabetes mellitus, hypertension, alcohol related disorders, chronic obstructive pulmonary disease, depression, use of oral contraceptives, hormone replacement therapy, and antithrombotic medication (acetylsalicylic acid, clopidogrel, and warfarin) and statin prior to diagnosis. 


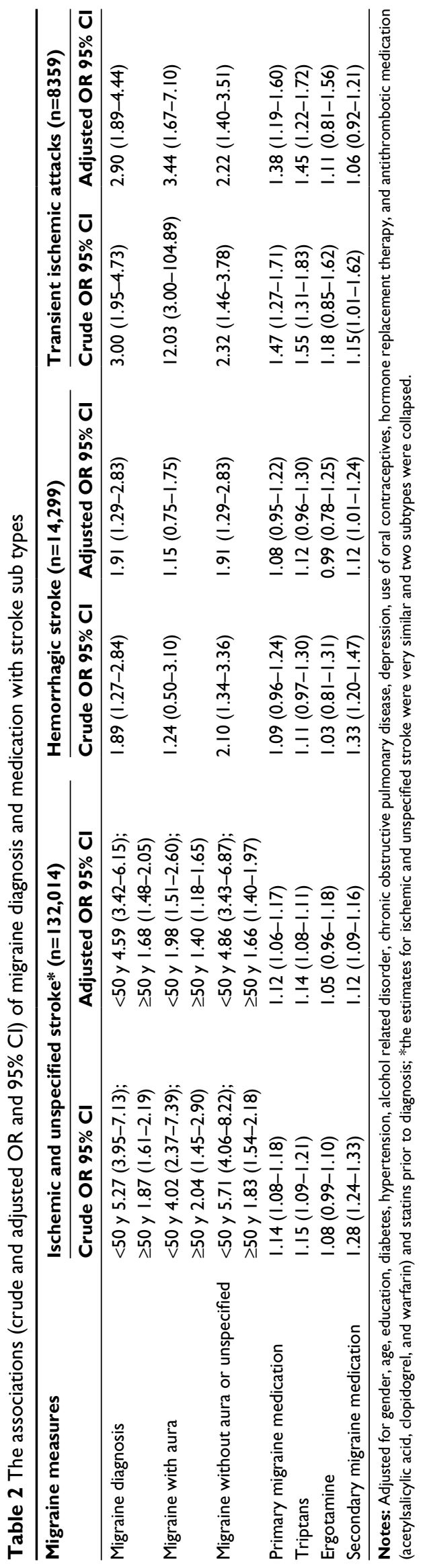

stroke patients who had used oral contraceptives or hormone replacement therapy seemed to have increased likelihood of being diagnosed with migraine compared with females with no history of hormone use but this potential interaction vanished when age was accounted for. All tests for statistical interaction between migraine medication use and co-variables had $p$ values $>0.10$.

The comparison of migraine indicators and the negative control exposure (use of general headache medication) in Table 3 showed that patients with diagnosis of migraine had 1.8 times higher odds of stroke than those who used general headache medication. Smaller, relative differences were seen for other migraine measures.

\section{Migraine and ACS}

Among the 97,799 patients with ACS, 268 (0.27\%) had diagnosis of migraine and 1814 (1.85\%) had used primary migraine medication. Among controls, the corresponding numbers were $145(0.15 \%)$ and $1729(1.78 \%)$, respectively (Figure 2).

In crude analyses, ACS patients had increased likelihood of being diagnosed with migraine (OR; 1.88 [95\% CI: 1.53-2.32]) in addition to a somewhat lower likelihood of using primary migraine medication (OR: 1.07 [95\% CI: $1.00-1.44]$ ), which was most evident for triptan use (OR: 1.10 [95\% CI: 1.02-1.18]) (Figure 2).

Among ACS cases and controls, diagnosis of migraine and use of migraine medication were most frequent among individuals $<50$ years, women, the highest educated, individuals with a diagnosis of depression or COPD, and among women who used hormones (Table S3). Adjustment for these cardiovascular risk factors slightly attenuated the ORs (Figure 2).

Analyses of ACS subtypes showed that a diagnosis of migraine was associated with increased odds for both unstable angina and AMI (STEMI, non-STEMI and unspecified), while primary migraine medication was only associated with increased odds for unstable angina (Table 4). Patients with unstable angina had higher likelihood of having a diagnosis of migraine with aura than patients with AMI (OR: 5.40 [95\% CI: 2.05-17.97] and OR: 1.46 [95\% CI: 0.86-2.50], $p$ test for interaction $=0.02$ ), but the estimates were imprecisely measured due to the low number of individuals.

The $40.7 \%$ of patients with diagnosis of migraine, who used primary migraine medication, seemed to have lower odds of ACS (OR: 1.42 [95\% CI: 1.04-1.97]) than migraineurs who had not used primary migraine medication (OR: 2.28 [95\% CI: 1.72-3.06]). However, this interaction 
vanished after adjustment for co-variables. Similarly, all other tests for statistical interaction between migraine and co-variables were insignificant.

Table 3 shows that patients with a diagnosis of migraine had $>2$ times higher odds of ACS than users of general headache medication. Similar smaller relative differences were seen for migraine medication.

\section{Discussion}

The present large, register-based case-control study showed that hospital diagnosis of migraine was clearly associated with increased odds of both stroke and ACS. Furthermore, use of triptans was also associated with slightly higher odds of stroke and ACS while use of ergotamine was not.

Table $3 \mathrm{OR}$ and $95 \% \mathrm{Cl}$ for migraine diagnosis, migraine medication use and other types of headache compared with general headache medication use in stroke and acute coronary syndrome patients versus controls

\begin{tabular}{lll}
\hline Migraine measures & $\begin{array}{l}\text { Stroke, OR } \\
\mathbf{9 5 \%} \mathbf{~ C l}\end{array}$ & $\begin{array}{l}\text { Acute coronary } \\
\text { syndrome, OR } \\
\mathbf{9 5 \%} \mathbf{C l}\end{array}$ \\
\hline Migraine diagnosis & $\mathrm{I} .75(\mathrm{I} .4 \mathrm{I}-2.13)$ & $2.47(2.19-2.17)$ \\
Primary migraine medication & $0.96(0.90-1.40)$ & $\mathrm{I} .1 \mathrm{I}(\mathrm{I} .06-1.16)$ \\
Secondary migraine medication & $\mathrm{I} .04(0.99-1.09)$ & $\mathrm{I} .26(\mathrm{I} .2 \mathrm{I}-\mathrm{I} .3 \mathrm{I})$ \\
Other types of headache & $\mathrm{I} .52(\mathrm{I} .2 \mathrm{I}-\mathrm{I} .92)$ & $\mathrm{I} .56(\mathrm{I} .35-\mathrm{I} .80)$ \\
General headache medication & $\mathrm{I}$ & $\mathrm{I}$ \\
None of above & $0.90(0.88-0.92)$ & $0.99(0.97-\mathrm{I} .0 \mathrm{I})$ \\
\hline
\end{tabular}

A diagnosis of migraine or use of migraine medication was associated with increased risk of all stroke and ACS subtypes with higher estimates for migraine with aura and TIA and unstable angina, however, in these analyses, estimates were hampered by lack of power. The associations between diagnosis of migraine and all stroke subtypes were higher in the youngest age group ( $<50$ years), while there was no statistical interaction between migraine and gender or use of oral contraceptives on a multiplicative scale.

Our study confirms the results from a number of studies showing that migraine is a risk factor for ischemic stroke. ${ }^{2,3-7}$ The present study also supports the fewer studies that indicate that migraine increases the risk of hemorrhagic stroke. ${ }^{10}$ We cannot exclude that the detected association between migraine and TIA is a spurious relation as it can be difficult to differentiate between migraine and TIA. ${ }^{4}$ In accordance with a few previous studies, ${ }^{12}$ diagnosis of migraine also seemed to increase the risk of ACS in the present study and this relation was not explained by adjustment for cardiovascular risk factors.

We used primary migraine medication (triptan and ergotamine) as proxy measures for migraine, but only triptan use seemed to be weakly associated with stroke. This finding is comparable with the results from a recent Danish registerbased cohort study on the association between triptan use and stroke. ${ }^{19}$ In this study, triptans were associated with increased risk of ischemic stroke (Relative Risk [RR]; 1.07

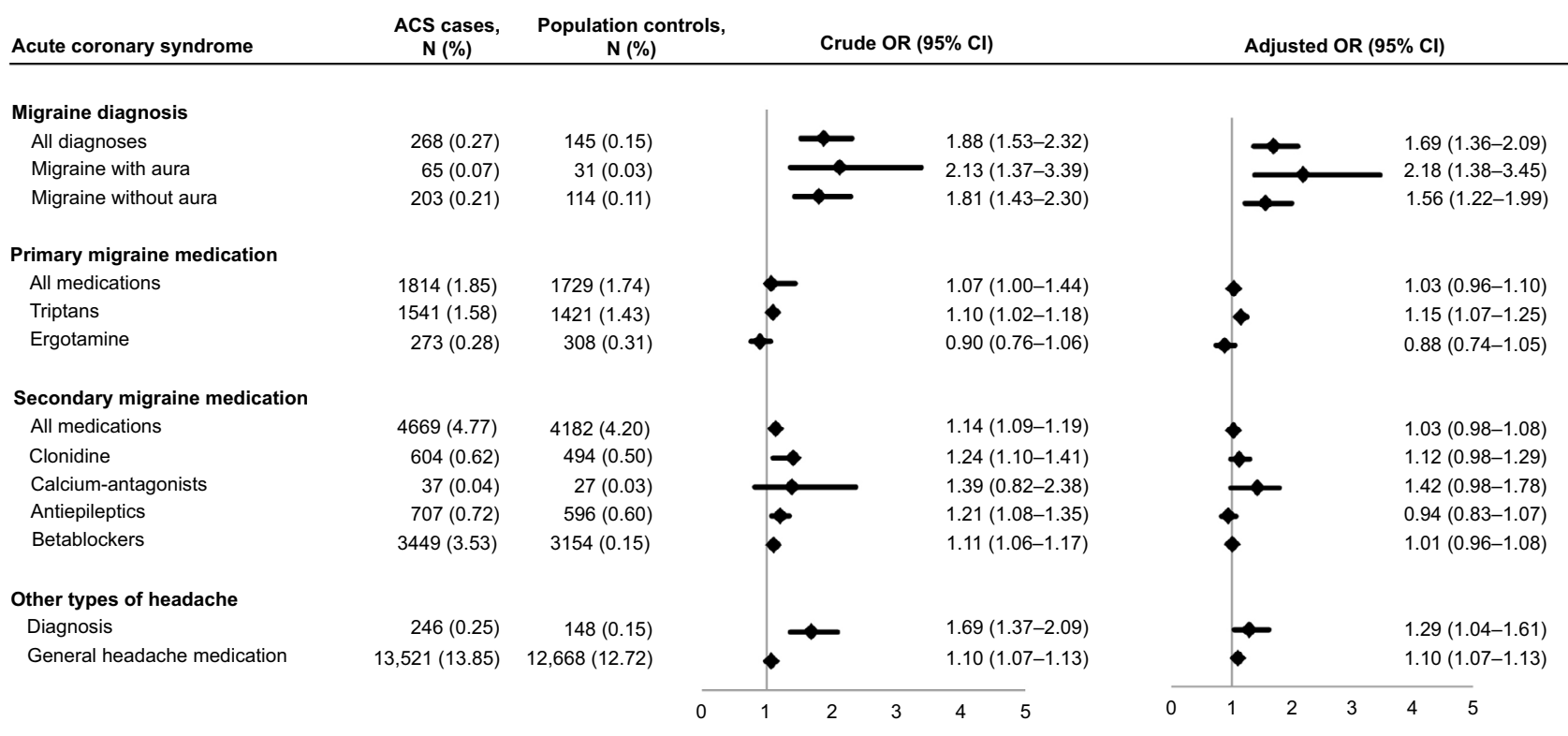

Figure 2 Associations (Crude and Adjusted odds ratio [OR] and 95\% Cl) between migraine and acute coronary syndrome (ACS) in 97,799 ACS patients and 99,6I8 controls. Notes: Adjusted for age, gender, education, diabetes mellitus, hypertension, alcohol related disorders, chronic obstructive pulmonary disease, depression, use of oral contraceptives, hormone replacement therapy, and antithrombotic medication (acetylsalicylic acid, clopidogrel, and warfarin) and statin prior to diagnosis.

Abbreviation: ACS, acute coronary syndrome. 
Table 4 The associations (adjusted OR and 95\% Cl) of migraine diagnosis and medication with acute coronary heart syndrome sub types

\begin{tabular}{|c|c|c|c|c|}
\hline \multirow[t]{2}{*}{ Migraine measures } & \multicolumn{2}{|l|}{ Angina $(n=20,521)$} & \multicolumn{2}{|c|}{ Acute myocardial infarction* $(n=77,278)$} \\
\hline & Crude OR 95\% CI & Adjusted OR 95\% Cl & Crude OR 95\% Cl & Adjusted OR $95 \% \mathrm{Cl}$ \\
\hline Migraine diagnosis & $2.75(1.86-4.16)$ & $2.25(1.48-3.48)$ & $\mathrm{I} .56(\mathrm{I} .22-2.0 \mathrm{I})$ & $1.32(1.02-1.71)$ \\
\hline Migraine with aura & $5.40(2.05-17.97)$ & $5.32(1.98-14.33)$ & $1.46(0.86-2.50)$ & $1.51(0.88-2.57)$ \\
\hline Migraine without aura or unspecified & $2.32(1.50-3.67)$ & $2.10(1.32-3.34)$ & $1.59(1.20-2.13)$ & $1.36(1.01-1.82)$ \\
\hline Primary migraine medication & $1.49(1.31-1.68)$ & $1.47(1.28-1.68)$ & $0.93(0.86-1.01)$ & $0.90(0.82-1.00)$ \\
\hline Triptans & $1.59(1.39-1.82)$ & $1.57(1.36-1.81)$ & $0.94(0.86-1.03)$ & $0.92(0.84-1.01)$ \\
\hline Ergotamine & $0.97(0.69-1.35)$ & $0.97(0.68-1.38)$ & $0.89(0.93-1.09)$ & $0.87(0.7 \mathrm{I}-\mathrm{I} .07)$ \\
\hline Secondary migraine medication & $1.48(1.35-1.62)$ & $1.30(1.17-1.13)$ & $1.05(0.99-1.10)$ & $0.94(0.89-1.00)$ \\
\hline
\end{tabular}

Notes: Adjusted for gender, age, education, diabetes, hypertension, alcohol related disorder, chronic obstructive pulmonary disease, depression, use of oral contraceptives, hormone replacement therapy, and antithrombotic medication (acetylsalicylic acid, clopidogrel, and warfarin) and statins prior to diagnosis; *STEMI, non-STEMI and unspecified. Abbreviation: STEMI, ST-elevation myocardial infarction.

[95\% CI:1.00-1.14]) and with hemorrhagic stroke in women (RR; 1.41 [95\% CI: 1.11-1.79]). In the present study, triptan use was associated with increased odds of angina but not with myocardial infarction. This might reflect that triptans seemed to trigger chest discomfort, ${ }^{20}$ which could be a potential source of bias. Our results seem to support the conclusions in a recent systematic review of the few observational studies investigating adverse cardiovascular events associated with triptan and ergotamine. The review study showed no clear evidence of prescribed use of triptan or ergotamine increases the risk of serious ischemic complications. ${ }^{21}$ For both stroke and ACS, the association between primary migraine medication use and each endpoint was weaker than the association for a hospital diagnosis of migraine. Patients with migraine solely identified by medication and without a hospital diagnosis most likely represent milder cases and the lower risk estimates could therefore suggest some degree of dose-response relation between severity of migraine and cardiovascular events. Consequently, our study could indicate that the increases in odds represent disease severity rather than drug-related phenomena.

We replicated the previous findings of a stronger association of diagnosis of migraine with all stroke subtypes in the youngest age group. For migraine with aura, the estimate for the youngest age group was higher than reported in recent meta-analyses. However, again this might reflect that our study is based on hospital diagnoses. Our analyses did not support the reports of higher odds estimated in females and users of contraceptives. ${ }^{4,6,7}$ Thus, in our study, a presumed interaction with hormone use vanished when the data were further stratified on age. Unfortunately, we had no information on current smoking, which might also influence the effect of migraine on stroke risk. We used COPD as proxy marker for heavy smoking but admit that this is a less valid measure of current smoking habits. Our study did not support our hypothesis that cardiovascular risk factors, including use of anti-thrombotic medication would influence the association between migraine and cardiovascular outcomes.

The mechanisms linking migraine and cardiovascular

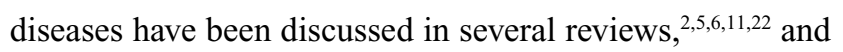
the most recent suggests that vascular dysfunction or small vessel disease might be important. ${ }^{6,19,23}$ Thrombotic mechanisms have also been suggested to link arterial dysfunction and vascular events, but in the present study, cardiovascular risk factors, including anti-thrombotic and -platelet treatment only explained a smaller part of the association between migraine and stroke and ACS, respectively.

The present study has strengths and limitations. First, the study was based on information on all incident strokes and ACS events from nationwide registers with high validity of stroke and ACS diagnoses and virtually without any losses. ${ }^{15,24,25}$ We had prospectively collected exposure data, which did not rely on patients' recall, making non-response and information bias unlikely explanations for our findings. Our definition of migraine was based on both hospital diagnoses and migraine medication prescription records and consequently, we might mainly have the most severe migraine cases. Thus, the results may not be transferable to milder cases. However, our estimates are comparable with those in previous reports based on validated questionnaires or physicians' diagnosis. An observational study as the present cannot answer whether the associations between migraine and stroke and ACS are caused by the exposure itself or whether migraine is a marker for adverse work and social environment, health or health behavior. It should, however, be highlighted that the detected associations were not explained by cardiovascular risk factors, although, we did not have information on smoking and serum lipids in the register data. On the other hand, we brought a more unspecific headache exposure into the analyses as negative control exposure. 
We assumed that these individuals in many ways might be similar to those with migraine. ${ }^{18}$ Use of general headache medication was also associated with increased risk of ACS, which could suggest that our estimates were hampered by residual confounding from unmeasured risk factors such as work and social environment and health behavior. However, when migraineurs' odds for stroke or ACS were compared with users of headache medication, thus accounting for assumed shared confounders (Table 3 ), the ORs for migraine remained elevated. This could suggest that the relation between migraine and the cardiovascular outcomes are due to shared pathogenesis and not explained by confounding. Finally, although the study was based on a large number of cases, the exposure was infrequent and the study did not have sufficient power to detect differences in odds between that is, migraine with aura and subtypes.

In conclusion, hospital-diagnosed migraine was associated with stroke and ACS independent of subtype with ischemic stroke and unstable angina having the highest odds. Age interacted with the association between a diagnosis of migraine and stroke, and the youngest age group had the highest odds. The associations were not explained by adjustment for confounding factors or when compared with general headache medication use with similar confounding but no assumed shared pathogenesis. Our results also indicate a degree of dose-response relation between severity of migraine and risk of cardiovascular events. Thus, clinicians should be aware of young patients with severe migraine with aura who seem to pose a risk for adverse vascular events.

\section{Acknowledgment}

The work was supported by the Danish Tryg Foundation (Idn 106450) and the Danish Heart Association (Bnr:14-R97-A5003-22834).

\section{Disclosure}

The authors report no conflicts of interest in this work.

\section{References}

1. Merikangas KR. Contributions of epidemiology to our understanding of migraine. Headache. 2013;53(2):230-246.

2. Mawet J, Kurth T, Ayata C. Migraine and stroke. In search of shared mechanisms. Cephalgia. 2015;35(2):165-181.

3. de Falco FA, de Falco A. Migraine with aura: which patients are most at risk of stroke? Neurol Sci. 2015;36(Suppl 1):S57-S60.
4. Kurth T, Charbriat H, Bousser MG. Migraine and stroke: a complex association with clinical implications. Lancet Neurol. 2012;11(1):92-100.

5. Spalice A, Del Balzo F, Papetti L, et al. Stroke and migraine is there a possible comorbidity. Italian J Pediatr. 2016;42:41.

6. Lee MJ, Lee C, Chung CS. The migraine-stroke connection. J Stroke. 2016;18(2):146-156.

7. Spector JT, Kahn SR, Jones MR, Yayakumar M, Dala D, Nazarian S. Migraine headache and ischemic stroke risk: an updated meta-analysis. Am J Med. 2010;123(7):612-624.

8. Schürks M, Rist PM, Bigal ME, Buring JE, Lipton RB, Kurth T. Migraine and cardiovascular disease: systematic review and metaanalysis. BMJ. 2009;339:b3914.

9. Etminan M, Takkouche B, Isorna FC, Samii A. Risk of ischemic stroke in people with migraine: systematic review and meta-analysis of observational studies. $B M J$. 2005;330(7482):63.

10. Sacco S, Ornello R, Ripa P, Pistoria F, Carolei A. Migraine and hemorrhagic stroke: a meta-analysis. Stroke. 2013;44(11):3032-3038.

11. Sacco S, Ripa P, Grassi D, al. Peripheral vascular dysfunction in migraine: a review. J Headache Pain. 2013;14(1):80.

12. Sacco S, Ornello R, Ripa P et al. Migraine and risk of ischaemic heart disease: a systematic review and meta-analysis of observational studies. Eur J Neurol. 2015;22(6):1001-1011.

13. Kurth T, Winter AC, Eliassen AH et al. Migraine and risk of cardiovascular disease in women: prospective cohort study. BMJ. 2016;353:i2610.

14. Gage SH, Munafó MR, Smith GD. Causal inference in developmental origins of health and disease (DOHaD) research. Ann Rev Psychol. 2016;67:567-585.

15. Schmidt M, Schmidt SA, Sandegaard JL, Ehrenstein V, Pedersen L, Sørensen HT. The Danish National Patient Registry: a review of content, data quality, and research potential. Clin Epidemiol. 2015;7:449-490.

16. Pottegård A, Schmidt SA, Wallach-Kildemoes H, Sørensen HT, Hallas J, Schmidt M. Data resource profile: The Danish National Prescription Registry. Int J Epidemiol. 2015;44:1-7.

17. Wium-Andersen IK, Wium-Andersen MK, Jørgensen MB, Osler M. Anti-inflammatory treatment and risk of depression in 91,842 patients with acute coroenary syndrome and 91, 860 individuals without acute coronary syndrome in Denamark. Int J Cardiol. In Press 2017.

18. Westergaard ML, Hansen EH, Glümer C, Jensen RH. Prescription pain medication and chronic headache in Denmark: implications for preventing medication overuse. Eur J Clin Pharamacol. 2015;71(7):851-860.

19. Albieri V, Olsen TS, Andersen KK. Risk of stroke in migraineurs using triptans: association with age, sex, stroke severity and subtype. EBioMedicine. 2016;6:199-205.

20. Thorlund $\mathrm{K}$, Toor $\mathrm{K}$, Wu P, et al. Comparative tolerability of treatments for acute migraine: a network meta-analysis. Cephaligia. Epub 2016 June 16 .

21. Roberto G, Raschi E, Piccini C et al. Adverse cardiovascular events associated with triptans and ergotamines for treatment of migraine: systematic review of observational studies. Cephalalgia. 2015;35(2):118-131.

22. Eikermann-Haerter K. Speading depolarization may link migraine and stroke. Headache. 2014;54(7):1146-1157.

23. Ripa P, Ornello R, Pistoia F, Carolei A, Sacco S. Spreading depolarization may link migraine, stroke and other cardiovascular diseases. Headache. 2015;55(1):180-182.

24. Joensen AM, Jensen MK, Overvad K et al. Predictive values of acute coronary syndrome discharge diagnoses differed in the Danish National Patient Registry. J Clin Epidemiol. 2009;62(2):188-194.

25. Johnsen SP, Overvad K, Sørensen HAT, Tjønneland A, Husted SE. Predictive value of stroke and transient ischemic attack discharge diagnosis in the Danish National Registry of Patients. J Clin Epidemiol. 2002;55(6):602-607. 


\section{Supplementary material}

Table SI ICD 10 and ATC codes used for generation of variables measuring comorbidity, hormones and anti-thrombotic medication

\begin{tabular}{lll}
\hline Variables & ICD-I0 & ATC \\
\hline Hypertension & IIO-II5 & C02; C03; C08; C09 \\
$\begin{array}{ll}\text { Chronic obstructive pulmonary disease } \\
\text { Diabetes }\end{array}$ & J40-J47; J96.I; J98.I-2 & R03 \\
Alcohol abuse & EI0; EII; EI4; H36.0 & AIO \\
& FI0; K70; T5I; G3I.2; G62.I; G72.I; I42.6; K29.2; K86.0; & N07BB \\
Depression & Z72.I; I48.6 & \\
Oral contraceptives & F3I-F33, F34 & N06A \\
Hormone replacement therapy & & G03A \\
Acetylsalicylic acid & & G03C; G03F \\
Statins & & B0IAC06, B0IAC56, N02BA0I, N02BA5I \\
Clopidogrel & & CI0AA \\
Warfarin & & B0IAC22, B0IAC04 \\
\hline
\end{tabular}

Abbreviation: ATC, anatomic therapeutical chemical.

Table S2 The distribution of covariables in relation to migraine diagnosis or medication in 155,216 first-time stroke patients and I56,905 population controls in Denmark 200I-20I I

\begin{tabular}{|c|c|c|c|c|c|c|}
\hline \multirow[t]{2}{*}{ Variables } & \multicolumn{3}{|l|}{ Stroke patients } & \multicolumn{3}{|c|}{ Population controls } \\
\hline & $\mathbf{N}(\%)$ & $\begin{array}{l}\mathrm{n}(\%) \text { with } \\
\text { migraine } \\
\text { diagnosis }\end{array}$ & $\begin{array}{l}\text { n (\%) used } \\
\text { migraine } \\
\text { medication }\end{array}$ & $\mathbf{N}(\%)$ & $\begin{array}{l}\text { n (\%) with } \\
\text { migraine } \\
\text { diagnosis }\end{array}$ & $\begin{array}{l}\mathrm{n}(\%) \text { used } \\
\text { migraine } \\
\text { medication }\end{array}$ \\
\hline \multicolumn{7}{|l|}{ Gender } \\
\hline Men & $78,435(50.53)$ & $279(0.36)$ & $1592(2.03)$ & 79418 (50.62) & $130(0.16)$ & $|43|(1.80)$ \\
\hline Women & 76,781 (49.47) & $695(0.91)$ & 3770 (4.91) & 77,487 (49.30) & $273(0.35)$ & $3244(4.19)$ \\
\hline \multicolumn{7}{|c|}{ Age (years) } \\
\hline$<50$ & I3,599 (8.76) & $360(2.65)$ & $1268(9.10)$ & 14,035 (8.94) & $79(0.56)$ & $827(5.89)$ \\
\hline $50-69$ & $53,887(34.72)$ & $386(0.72)$ & $2488(4.62)$ & $55,456(35.34)$ & $207(0.37)$ & $2346(4.23)$ \\
\hline$\geq 70$ & $87,730(56.52)$ & $228(0.26)$ & $1636(1.86)$ & $87,4 \mid 4(55.7 I)$ & $117(0.13)$ & $1499(1.71)$ \\
\hline \multicolumn{7}{|l|}{ Education } \\
\hline Higher & $|5,75|(10.15)$ & $152(0.97)$ & $830(5.27)$ & $20,730(\mid 3.21)$ & $88(0.42)$ & $1730(2.81)$ \\
\hline Middle & $46,735(30.11)$ & $334(0.7 I)$ & $1897(4.06)$ & 48,809 (3I.II) & $134(0.27)$ & $1697(3.48)$ \\
\hline Basic & $65,94 \mathrm{I}(42.48)$ & $419(0.64)$ & $226 \mathrm{I}(3.43)$ & 61,606 (39.26) & $156(0.25)$ & $1730(2.81)$ \\
\hline Unknown & $26,789(17.26)$ & $67(0.25)$ & $375(1.40)$ & $25,760(16.42)$ & $25(0.10)$ & $290(1.13)$ \\
\hline \multicolumn{7}{|l|}{ Diabetes } \\
\hline No & I36,272 (87.80) & $885(0.65)$ & $4907(3.60)$ & |44,99| (92.4I) & $380(0.26)$ & $4449(3.07)$ \\
\hline Yes & $18,944(12.20)$ & $189(1.00)$ & $455(2.40)$ & II,9|4 (7.59) & $23(0.19)$ & $226(1.90)$ \\
\hline \multicolumn{7}{|c|}{ Hypertension } \\
\hline No & $56,310(36.28)$ & $428(0.76)$ & $205 I(3.64)$ & 76,757 (48.92) & $170(0.22)$ & $2266(2.95)$ \\
\hline Yes & 98,906 (63.72) & $546(0.55)$ & $3311(3.35)$ & $80,148(51.08)$ & $233(0.29)$ & $2409(3.01)$ \\
\hline \multicolumn{7}{|c|}{ Chronic obstructive pulmonary disease } \\
\hline No & || $4,88 \mid(74.00)$ & $598(0.52)$ & $3329(2.90)$ & I2I,645 (79.53) & $268(0.22)$ & $3242(2.67)$ \\
\hline Yes & $40,335(26.00)$ & $376(0.93)$ & $2033(5.04)$ & $35,260(22.47)$ & $135(0.38)$ & $1433(4.06)$ \\
\hline \multicolumn{7}{|c|}{ Major depression } \\
\hline No & III,305 (7I.7I) & $510(0.46)$ & $2890(2.60)$ & $124,625(79.43)$ & $207(0.17)$ & $3070(2.46)$ \\
\hline Yes & $43,911(28.29)$ & $464(1.06)$ & $2472(5.63)$ & $32,280(20.57)$ & $196(0.61)$ & $1605(4.97)$ \\
\hline \multicolumn{7}{|c|}{ Alcohol abuse } \\
\hline No & $143,704(92.58)$ & $894(0.62)$ & $4929(3.43)$ & $152,083(96.93)$ & $391(0.26)$ & $4553(2.99)$ \\
\hline Yes & II,5 I $2(7.42)$ & $80(0.69)$ & $433(3.76)$ & $4822(3.07)$ & $12(0.25)$ & $122(2.53)$ \\
\hline \multicolumn{7}{|c|}{ Oral contraceptives (women) } \\
\hline No & $71,205(92.74)$ & $470(0.66)$ & $2914(4.09)$ & $71,803(92.66)$ & $215(0.30)$ & $2648(3.69)$ \\
\hline Yes & $5576(7.26)$ & $225(4.04)$ & $856(15.35)$ & $5684(7.34)$ & $58(1.02)$ & $596(10.49)$ \\
\hline \multicolumn{7}{|c|}{ Hormone replacement therapy (women) } \\
\hline No & $49,542(69.52)$ & $396(0.80)$ & $1944(3.92)$ & $50,082(64.63)$ & $124(0.25)$ & $1629(3.25)$ \\
\hline Yes & $27,239(35.48)$ & $297(1.09)$ & $1826(6.70)$ & $27,405(35.37)$ & $149(0.54)$ & $1615(5.89)$ \\
\hline
\end{tabular}

(Continued) 
Table S2 (Continued)

\begin{tabular}{|c|c|c|c|c|c|c|}
\hline \multirow[t]{2}{*}{ Variables } & \multicolumn{3}{|l|}{ Stroke patients } & \multicolumn{3}{|c|}{ Population controls } \\
\hline & $\mathbf{N}(\%)$ & $\begin{array}{l}\text { n (\%) with } \\
\text { migraine } \\
\text { diagnosis }\end{array}$ & $\begin{array}{l}\text { n (\%) used } \\
\text { migraine } \\
\text { medication }\end{array}$ & $\mathbf{N}(\%)$ & $\begin{array}{l}\text { n (\%) with } \\
\text { migraine } \\
\text { diagnosis }\end{array}$ & $\begin{array}{l}\text { n (\%) used } \\
\text { migraine } \\
\text { medication }\end{array}$ \\
\hline \multicolumn{7}{|c|}{ Medication with anti-thrombotic properties ASA } \\
\hline No & $132,890(85.62)$ & $596(0.66)$ & $3384(3.72)$ & $124,164(79.13)$ & $275(0.25)$ & $3559(3.19)$ \\
\hline Yes & $22,326(14.38)$ & $378(0.59)$ & $1978(3.08)$ & $32,74 \mathrm{I}(20.87)$ & $128(0.28)$ & $1116(2.47)$ \\
\hline \multicolumn{7}{|c|}{ Clopidogrel } \\
\hline No & $149,643(96.64)$ & $902(0.60)$ & $5152(3.44)$ & $153,142(97.60)$ & $389(0.25)$ & $4583(2.99)$ \\
\hline Yes & $5573(3.36)$ & $72(1.29)$ & $210(3.77)$ & $3763(2.40)$ & $14(0.37)$ & $92(2.44)$ \\
\hline \multicolumn{7}{|l|}{ Warfarin } \\
\hline No & $140,268(90.37)$ & $903(0.64)$ & $498 \mid(3.55)$ & $|47,4| 8(93.95)$ & $389(0.26)$ & $4476(3.04)$ \\
\hline Yes & $14,948(9.63)$ & $71(0.47)$ & $38 \mathrm{I}(2.55)$ & $9487(6.05)$ & $14(0.15)$ & $199(2.10)$ \\
\hline \multicolumn{7}{|l|}{ Statin } \\
\hline No & I25,707 (80.99) & $74 \mid(0.59)$ & $4288(3.4 I)$ & $|32,40|(84.38)$ & $329(0.25)$ & $3948(2.98)$ \\
\hline Yes & $29,509(19.01)$ & $233(0.79)$ & $1074(3.64)$ & 24,504 (I5.62) & $74(0.30)$ & 727 (2.97) \\
\hline
\end{tabular}

Abbreviation: ASA, acetylsalicylic acid.

Table S3 The distribution of covariables in relation to migraine diagnosis or medication in 97,799 Danish patients with first time acute coronary heart syndrome (ACS) and 99,618 population controls in Denmark 200I-2009.

\begin{tabular}{|c|c|c|c|c|c|c|}
\hline \multirow[t]{2}{*}{ Variables } & \multicolumn{3}{|l|}{ ACS patients } & \multicolumn{3}{|c|}{ Population controls } \\
\hline & $\mathbf{N}(\%)$ & $\begin{array}{l}\text { n (\%) with } \\
\text { migraine } \\
\text { diagnosis }\end{array}$ & $\begin{array}{l}\text { n (\%) used } \\
\text { migraine } \\
\text { medication }\end{array}$ & $\mathbf{N}(\%)$ & $\begin{array}{l}\text { n (\%) with } \\
\text { migraine } \\
\text { diagnosis }\end{array}$ & $\begin{array}{l}\mathbf{n}(\%) \text { used } \\
\text { migraine } \\
\text { medication }\end{array}$ \\
\hline \multicolumn{7}{|l|}{ Gender } \\
\hline Men & 60,365 (61.72) & $99(0.16)$ & $692(1.15)$ & $61,548(61.78)$ & $64(0.10)$ & $668(1.09)$ \\
\hline Women & $37,434(38.28)$ & $169(0.45)$ & $1122(3.00)$ & $38,070(38.22)$ & $81(0.21)$ & $106 \mid(2.79)$ \\
\hline \multicolumn{7}{|c|}{ Age (year) } \\
\hline$<50$ & $10,553(10.75)$ & $70(0.66)$ & $479(4.54)$ & $10,764(21.38)$ & $31(0.29)$ & $356(3.31)$ \\
\hline $50-69$ & $39,924(40.81)$ & $125(0.31)$ & $957(2.40)$ & $40,736(40.87)$ & $77(0.19)$ & $926(2.27)$ \\
\hline$\geq 70$ & $47,322(48.45)$ & $73(0.15)$ & $378(0.80)$ & $48,118(48.34)$ & $37(0.08)$ & $447(0.93)$ \\
\hline \multicolumn{7}{|l|}{ Education } \\
\hline Higher & $964 \mid(8.85)$ & $30(0.31)$ & $303(3.13)$ & $13,922(13.98)$ & $21(0.15)$ & $380(2.73)$ \\
\hline Middle & 31,728 (32.54) & $98(0.31)$ & $607(1.91)$ & $33,406(33.54)$ & $45(0.13)$ & $653(1.95)$ \\
\hline Basic & $41,549(42.50)$ & $116(0.28)$ & $780(1.80)$ & 37,721 (37.87) & $69(0.18)$ & $598(1.59)$ \\
\hline Unknown & $|4,88|(\mid 5.07)$ & $24(0.10)$ & $124(0.84)$ & $14,569(14.62)$ & $10(0.07)$ & $98(0.67)$ \\
\hline \multicolumn{7}{|l|}{ Diabetes } \\
\hline No & $84,602(86.74)$ & $244(0.29)$ & $1652(1.95)$ & 92,718 (93.07) & $134(0.14)$ & I647 (I.78) \\
\hline Yes & $12,929(13.26)$ & $24(0.19)$ & $162(1.25)$ & $6900(6.93)$ & $11(0.16)$ & $82(1.19)$ \\
\hline \multicolumn{7}{|c|}{ Hypertension } \\
\hline No & $40,342(41.25)$ & $101(0.25)$ & $786(1.95)$ & $56,4 I 5(56.63)$ & $77(0.14)$ & $1032(1.83)$ \\
\hline Yes & $57,457(58.75)$ & $167(0.29)$ & $1028(1.79)$ & $43,203(43.37)$ & $68(0.16)$ & $697(1.61)$ \\
\hline \multicolumn{7}{|c|}{ Chronic obstructive pulmonary disease } \\
\hline No & $76,701(78.43)$ & $196(0.26)$ & $1276(1.66)$ & 84,068 (84.39) & $118(0.14)$ & $139 \mid(1.65)$ \\
\hline Yes & $21,098(21.57)$ & $72(0.34)$ & $538(2.55)$ & $15,550(15.61)$ & $27(0.17)$ & $338(2.17)$ \\
\hline \multicolumn{7}{|c|}{ Major depression } \\
\hline No & $73,603(75.26)$ & $127(0.17)$ & $1015(1.38)$ & $79,767(80.07)$ & $87(0.11)$ & $1152(1.44)$ \\
\hline Yes & $24,196(24.74)$ & $|4|(0.58)$ & $799(3.30)$ & $|9,85|(19.93)$ & $58(0.29)$ & $577(2.91)$ \\
\hline \multicolumn{7}{|c|}{ Alcohol abuse } \\
\hline No & $94,474(96.60)$ & $255(0.27)$ & $1727(1.83)$ & $96,954(97.33)$ & $143(0.15)$ & $1696(1.75)$ \\
\hline Yes & $3325(3.40)$ & $13(0.39)$ & $87(2.62)$ & $2664(2.67)$ & $2(0.08)$ & $33(1.24)$ \\
\hline \multicolumn{7}{|c|}{ Oral contraceptives (women) } \\
\hline No & $35,110(93.79)$ & $|4|(0.40)$ & $898(2.56)$ & $35,717(93.82)$ & $66(0.18)$ & $885(2.48)$ \\
\hline Yes & $2324(6.21)$ & $28(1.20)$ & $224(9.64)$ & $2353(6.18)$ & $15(0.64)$ & $176(7.48)$ \\
\hline \multicolumn{7}{|c|}{ Hormone replacement therapy (women) } \\
\hline No & $24,002(64.12)$ & $90(0.37)$ & $576(2.40)$ & $25,009(65.69)$ & $44(0.18)$ & $562(2.25)$ \\
\hline Yes & $13,432(35.88)$ & 79 (0.59) & $546(4.06)$ & $|3,06|(34.31)$ & $37(0.28)$ & $499(3.82)$ \\
\hline
\end{tabular}


Table S3 (Continued)

\begin{tabular}{|c|c|c|c|c|c|c|}
\hline \multirow[t]{2}{*}{ Variables } & \multicolumn{3}{|l|}{ ACS patients } & \multicolumn{3}{|c|}{ Population controls } \\
\hline & $\mathbf{N}(\%)$ & $\begin{array}{l}\text { n (\%) with } \\
\text { migraine } \\
\text { diagnosis }\end{array}$ & $\begin{array}{l}\text { n (\%) used } \\
\text { migraine } \\
\text { medication }\end{array}$ & $\mathbf{N}(\%)$ & $\begin{array}{l}\text { n (\%) with } \\
\text { migraine } \\
\text { diagnosis }\end{array}$ & $\begin{array}{l}\text { n (\%) used } \\
\text { migraine } \\
\text { medication }\end{array}$ \\
\hline \multicolumn{7}{|c|}{ Medication with anti-thrombotic properties ASA } \\
\hline No & $56,315(57.58)$ & $147(0.26)$ & $1183(2.10)$ & $73,363(73.64)$ & $95(0.13)$ & $1354(1.85)$ \\
\hline Yes & $4 I, 484(42.42)$ & $|2|(0.29)$ & $631(1.52)$ & $26,255(26.36)$ & $50(0.19)$ & $375(1.43)$ \\
\hline \multicolumn{7}{|c|}{ Clopidogrel } \\
\hline No & $94,509(96.64)$ & $25 I(0.27)$ & $1763(1.87)$ & $98,749(99.13)$ & $142(0.14)$ & $1709(1.73)$ \\
\hline Yes & $3290(3.36)$ & $17(0.52)$ & $51(1.55)$ & $869(0.97)$ & $3(0.35)$ & $20(2.30)$ \\
\hline \multicolumn{7}{|l|}{ Warfarin } \\
\hline No & $90,38 \mathrm{I}(92.42)$ & $248(0.27)$ & $1733(1.92)$ & $93,910(94.27)$ & $137(0.15)$ & I67| (1.78) \\
\hline Yes & $74 \mid 8$ (7.58) & $20(0.27)$ & $81(1.09)$ & $5708(5.73)$ & $8(0.14)$ & $58(1.02)$ \\
\hline \multicolumn{7}{|l|}{ Statin } \\
\hline No & 76,050 (77.76) & $193(0.25)$ & 1409 (1.85) & $87,884(88.22)$ & $12 \mid(0.14)$ & $1544(1.76)$ \\
\hline Yes & $21,749(22.24)$ & $75(0.34)$ & $405(1.86)$ & II,734 (I I.78) & $24(0.20)$ & I85 (I.58) \\
\hline
\end{tabular}

Abbreviation: ASA, acetylsalicylic acid.

Clinical Epidemiology

\section{Publish your work in this journal}

Clinical Epidemiology is an international, peer-reviewed, open access, online journal focusing on disease and drug epidemiology, identification of risk factors and screening procedures to develop optimal preventative initiatives and programs. Specific topics include: diagnosis, prognosis, treatment, screening, prevention, risk factor modification,

Submit your manuscript here: https://www.dovepress.com/clinical-epidemiology-journal

\section{Dovepress}

systematic reviews, risk and safety of medical interventions, epidemiology and biostatistical methods, and evaluation of guidelines, translational medicine, health policies and economic evaluations. The manuscript management system is completely online and includes a very quick and fair peer-review system, which is all easy to use. 